\title{
A METHOD FOR THE DETERMINATION OF THE AMOUNT OF OXYGEN AND CARBON DIOXIDE IN THE MIXED VENOUS BLOOD OF MAN
}

\author{
By C. SIDNEY BURWELL AND G. CANBY ROBINSON
}

(From the Medical Clinic, Johns Hopkins Hospital)

(Received for publication, June 20, 1924)

\section{INTRODUCTION}

The exchange of gases between the blood and the fixed tissues of the body is essential for life. It is accomplished by a complex mechanism adapted to meet the ever changing conditions of the cells of the animal organism. Quantitative studies of this vital phenomenon are of importance because knowledge of the amount of oxygen lost or of carbon dioxide accumlated by a unit of blood in its passage through the body is not only in itself significant but also allows the calculation of the output of the heart per minute according to the principle of Fick (1870). When the heart rate is also known, the output of the heart per beat may be calculated; and this, Yandell Henderson states, is probably both for physiological and clinical purposes the most important quantitative function of the body. The study reported in this paper was initiated with the purpose of measuring the output of the heart.

Calculation of the cardiac output by Fick's principle demands a knowledge of two facts: (1) the amount of oxygen absorbed by the body per minute and (2) the amount of oxygen taken up by each unit of blood as it passes through the lungs. Division of the total oxygen per minute by the oxygen taken up by each unit of blood will express the number of units of blood passing through the lungs each minute. The determination of the oxygen taken up by each unit of blood requires knowledge of (1) the oxygen content of the blood as it leaves the lungs (arterial blood) and (2) the oxygen content of the blood as it enters the lungs (mixed venous blood).

Fick's principle may be applied as well if the corresponding figures for carbon dioxide are known. 


\section{GASEOUS CONTENT OF THE MIXED VENOUS BLOOD}

In lower animals arterial blood and true venous blood are obtained by direct puncture of the left and right ventricles but this method can not be applied to man. Arterial blood can be obtained safely and conveniently in human subjects by artery puncture, as described by Stadie (1919). To obtain mixed venous blood is, however, less simple, since there is abundant evidence to show that blood from a superficial vein may have a gas content quite different from that of the blood which, collected from the entire body, finally enters the lungs as the mixed venous blood. (Uyeno and Doi (1922); Barcroft and Nagahaski (1921); Meakins and Davies (1922); Dautrebande, Davies and Meakins (1923); Peters, Barr and Rule (1921); Meakins, Dautrebande and Fetter (1923); Stewart (1923).)

It is necessary, therefore, that the measurement of the gas content of the mixed venous blood be approached indirectly. The problem may be approached by way of the lungs, using a respiratory method of the sort devised in the laboratory of Pflüger, who first suggested the use of the lungs as an aerotonometer. When blood comes in contact with air in the lungs, the gases in the blood and in the lung air tend to come into pressure equilibrium If a gas mixture is held in the lungs, it takes up gases from the blood or gives them up to the blood according to whether the gas tensions in the mixture are lower or higher than those of the blood entering the lungs. This principle has withstood the attack initiated by Bohr (Barcroft, 1914), and seems firmly established. It is generally accepted that blood exposed at a given temperature to a given gas tension will contain the same amount of gas whether in a tonometer or in the lungs.

The tension of oxygen and of carbon dioxide in the mixed venous blood may be determined by the analysis of air after its equilibration in the lungs with the blood entering them. The tensions being known, the contents may be calculated by applying the tensions to the dissociation curves of the two gases for the blood of the individual subject. Upon these principles several methods for the determination of the gases of the mixed venous blood have been evolved, which overcome the various technical difficulties with more or less success. The contributions of Loewy and v. Schrötter (1905); Plesch (1909); Henderson and Prince (1914); Meakins and Davies (1922); Christiansen, Douglas and Haldane (1914); Douglas and Haldane (1922); Fridericia (1918); Barcroft, Roughton and Shoji (1921); and Redfield, Bock and Meakins (1922) are especially noteworthy.

Reviews have recently been published by Henderson (1923) and by Wiggers (1923), and further mention of previous methods will be made therefore only as they are related directly to the one we shall describe.

The basic principle utilized by all previous methods is the determination by respiratory methods of the tension of oxygen or carbon dioxide in the mixed venous blood, and then the calculation by means of dissociation curves of the gas content of the blood at the tension determined. It has been shown that the amount of these gases taken up by blood when exposed to them at given tensions varies with different individuals; and that the tension of each gas involved influences the 
dissociation curve of the other. Furthermore, when the physiological processes are disturbed by the changes incident to disease the dissociation curves may be no longer constant for the individual and should be determined at the time the gas tensions are determined. Therefore it appears that the application of gas tensions to dissociation curves not only entails a considerable technical burden but is open to the criticism of being indirect and perhaps untrustworthy in diseased subjects. We have devised a method in which the application of dissociation curves is not made.

\section{THE METHOD}

The general principles of the method we have devised are as follows. By a respiratory method a gas mixture is obtained in which both the oxygen and the carbon dioxide are in equilibrium with these gases of the mixed venous blood. A tonometer is filled directly with this gas and blood of the subject is equilibrated with it under standard conditions. Blood so treated is, as it were, "artificial" mixed venous blood and its analysis supplies the data of which we are in search. The respiratory procedure is readily accomplished by untrained subjects under conditions suitable for the study of hospital patients.

The gas tension of the blood. We attacked the problem of obtaining the desired gas mixture by utilizing the method of Henderson and Prince. A rubber bag was filled with about 2,000 cc. of air, and this was inspired by the subject after a deep expiration. Following the recommendation of Laurens (1918) the air was breathed back and forth several times within a period of ten seconds. After the third expiration into the bag it was closed by turning the tap, and a sample of the gas taken. After an interval of three minutes the process was repeated; the series of samples thus obtained represented the original contents of the bag modified during each period by the mixture of the residual lung air and contact with the blood flowing through the lungs. The samples were analysed in duplicate for oxygen and carbon dioxide with the Henderson modification of the Haldane apparatus.

In such a series of samples the $\mathrm{CO}_{2}$ tension usually became fixed after 4 to 6 rebreathings at about $45 \mathrm{~mm}$. and did not thereafter change no matter how many times rebreathed. The oxygen tension became fixed more slowly, the number of rebreathings necessary depending upon the composition of the gas mixture originally in the 
bag, but eventually (after 6 to 9 rebreathings) it showed no further change, but remained at about $80 \mathrm{~mm}$. It was evident that although the $\mathrm{CO}_{2}$ of the gas mixture might be in equilibrium with that of the mixed venous blood the oxygen was not, as with an oxygen tension of $80 \mathrm{~mm}$. the venous blood would be over 90 per cent saturated, which is obviously not the case. Such a rebreathing method is not to be expected to give an oxygen tension in equilibrium with the venous blood, as between each rebreathing period, room air containing approximately 21 per cent of oxygen is drawn into the lungs, and at least $1,000 \mathrm{cc}$. of residual air containing 16 per cent oxygen remains in the lungs at the beginning of each rebreathing period. It is clear, as Plesch and others have pointed out, that before the contents of the bag are taken into the lungs a preliminary adjustment of the lung air must be made which reduces the oxygen to a point near that of the venous blood, in order to permit the oxygen of the lung air to come into equilibrium with that of the venous blood during the short time available for the exposure of the air to the blood. This reduction of the oxygen of the lung air was accomplished by taking two breaths of a low-oxygen mixture just before each rebreathing. This mixture was made up so that the lung air after two full breaths of the mixture had $\mathrm{CO}_{2}$ and oxygen tensions approximating those of the mixed venous blood. The samples of lung air were obtained by means of a Haldane tube into which was expired the second breath of the lowoxygen diluting mixture.

When each rebreathing was preceded by such a preliminary adjustment of the lung air, it was found that the fixation of oxygen tension occurred at a point not incompatible with previously known physiological facts and that this point varied but slightly in successive determinations on the same individual.

It was then necessary to devise a method for determining the amount of oxygen in the mixture which should be breathed in order to reduce the lung air to approximately that of the venous blood, and to test the assumption that a constant tension was reached which actually represented the oxygen tension of the mixed venous blood. The method that was used for this purpose consisted in carrying on simultaneously two similar experiments, using two large spirometers containing gas mixtures of somewhat different oxygen tensions, so adjusted that the 
lung air obtained after two inspirations from one spirometer had a higher oxygen tension than that of the supposed venous blood, while the lung air obtained after two inspirations from the other spirometer had a lower oxygen tension than that of the supposed venous blood. The two rebreathing bags were used alternately, so that conditions were the same throughout all rebreathing periods. Each bag was filled at the onset with an expiration following two full inspirations from the corresponding spirometer, and then at three minute intervals, the air in one or the other bag was rebreathed three times following two full inspirations from one or the other spirometer. When the spirometers contained properly adjusted gas mixtures, the successive samples taken from one bag showed a lower oxygen tension after such rebreathing down to a point where no further change occurred, while the successive samples from the other bag showed a higher oxygen

TABLE 1

\begin{tabular}{|c|c|c|}
\hline & $\begin{array}{l}\text { Spirometer I } \\
\left(\mathrm{O}_{2} \text { tension }\right)\end{array}$ & $\begin{array}{l}\text { Spirometer } I I \\
\left(\mathrm{O}_{2} \text { tension }\right)\end{array}$ \\
\hline & mm. $\mathrm{Hg}$ & mm. Hg \\
\hline Spirometer mixture $\ldots \ldots \ldots \ldots \ldots \ldots \ldots$ & 10.4 & 6.8 \\
\hline Alveolar sample $\ldots \ldots \ldots \ldots \ldots \ldots \ldots \ldots$ & 32.0 & 27.6 \\
\hline 9th rebreathing $\ldots \ldots \ldots \ldots \ldots \ldots \ldots \ldots \ldots \ldots \ldots$ & 31.4 & 30.9 \\
\hline
\end{tabular}

tension after each rebreathing up to a point where no further change occurred. The points where the successive samples remained constant were almost identical in the samples from the two bags. It was evident, therefore, that the oxygen tension in the two bags at the end of such a procedure was that of the mixed venous blood. A large number of such experiments were conducted on the same individual under fairly constant conditions of rest in order to determine not only the most suitable oxygen mixture but also the rapidity and accuracy with which the oxygen of the lung air came into equilibrium with the oxygen of the mixed venous blood. Table 1 gives the results of such an experiment. These figures together with other evidence that is not published furnish evidence that the oxygen tension of the gas mixture in the rebreathing bag may be brought into equilibrium with that of the blood entering the lungs when the oxygen of the lung air is properly diluted before each rebreathing. It was 
found that the proper dilution of the oxygen of the lung air was brought about by inspiring a mixture containing from 0.7 to 2 per cent oxygen.

However, the two inspirations for reducing the oxygen also reduced the carbon dioxide of the lung air, so that the final carbon dioxide figure in the bag was too low. It was evident that if it was necessary to breathe a low oxygen mixture to reduce the oxygen it was necessary to breathe a high $\mathrm{CO}_{2}$ mixture to maintain the $\mathrm{CO}_{2}$ tension. It was found that when the diluting mixture contained 6 to 7 per cent $\mathrm{CO}_{2}$ the lung air after two diluting breaths had a $\mathrm{CO}_{2}$ tension of about 45 $\mathrm{mm}$. $\mathrm{Hg}$ and gave final mixtures in the bag which were only slightly lower than obtained by the method of Henderson and Prince. This slight discrepancy is assumed to be due to the difference in the oxygen saturation of the blood.

The gas mixture for adjusting the lung air was made up by introducing commercial nitrogen, room air, and carbon dioxide in a 100 liter spirometer. It was found important to mix the gases after they were run into the spirometer in order to get a constant mixture during experiments. Because of changes which occur in the gas mixture on standing over the water in the spirometer, it was made up immediately before it was used, and samples for analysis were withdrawn immediately after the rebreathing procedure.

The respiratory procedure. The method of carrying out the respiratory procedure was as follows. All data were obtained under constant conditions of bodily exercise, of the taking of food, of room temperature and as far as possible of psychic activity. The subject was placed in a reclining chair and rested for a period of about half an hour and until the heart rate became slowed to 72 beats per minute or less. The apparatus was arranged as shown in figure 1 . The breathing tube was adjusted so that it was exactly at the level of the subject's mouth, and only a slight movement of the head was necessary to remove the mouth from the apparatus. No other movements were allowed during the experiment. (In the last few experiments an additional 3-way cock has been attached to the breathing tube, so that the subject could remain connected to the apparatus by a rubber mouth-piece and still breathe from room air, spirometer, or bag as occasion demanded.) The tube from the spirometer was attached to a respiratory valve which in turn was attached directly to one arm 
of a 3-way stop-cock. The rebreathing bag was attached to the other arm, so arranged that by turning the cock, the subject was in connection either with the spirometer or with the rebreathing bag. When all was adjusted the subject inspired two or three times from the spirometer, thus filling all tubes with the gas mixture. The last expiration was directed by the operator into the rebreathing bag by turning the stop-cock at the end of the last inspiration from the spirometer, the bag having been previously empty. The tape of

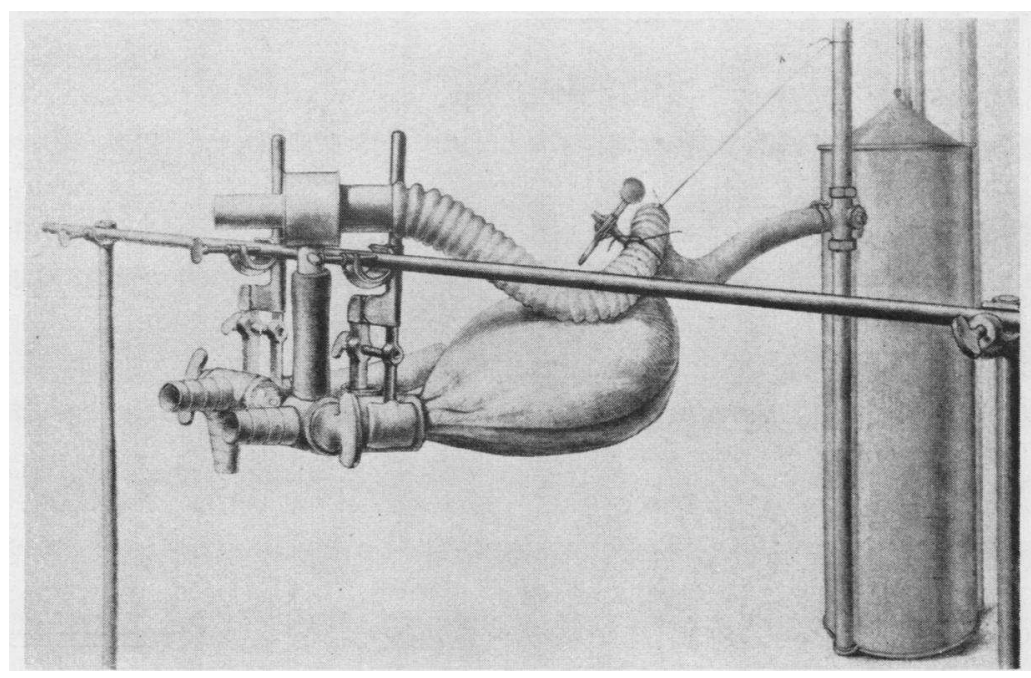

Fig. 1. Thy. Apparates for Carrying Ott the Respiratory ProCEDURE

The stop-cock of the Haldane-Priestly tube is also shown

the spirometer was then read in order to record the amount of the gas mixture used each time for adjusting the lung air, and the subject was encouraged to keep this amount fairly constant. As a rule about 60 per cent of the subject's vital capacity in each of the two respirations was found satisfactory. The fact that slight variations in the depth of the inspirations did not materially influence the rebreathing results was repeatedly demonstrated.

A typical respiratory procedure may be described as follows. The nose of the subject is closed with a nose clip and he applies his 
mouth to the breathing tube and expires fully, the cock being turned so that the expiration escapes to the outside air. He then takes five full breaths, the stop-cock being turned at the end of the expiration following the second inspiration from the spirometer, so that the third, fourth and fifth breaths are in and out of the bag. At the end of the last expiration into the bag the cock is again turned, shutting off the bag, and the subject is directed to move the mouth from the breathing tube and to breathe outside air. The entire procedure requires from eighteen to twenty seconds, divided equally between the inspirations from the spirometer and the rebreathing to and from the bag. The procedure can be carried out correctly by ordinary hospital patients with little or no practice. The subject is fairly dyspnoeic for five or six breaths after the rebreathing and may show moderate cyanosis, but there is no change in heart rate. This procedure is repeated seven to eleven times, with an interval of three minutes between each. When samples are required they are taken from the bag immediately after each rebreathing so that diffusion of gases through the rubber bag plays no part in the results.

In order to demonstrate the changes that take place in the $\mathrm{CO}_{2}$ and oxygen tensions during each rebreathing a series of analyses was made. The spirometer contained at the end of the experiment a mixture having a $\mathrm{CO}_{2}$ tension of $45.6 \mathrm{~mm}$. (6.45 per cent) and an oxygen tension of $6.7 \mathrm{~mm}$. ( 0.94 per cent). The rebreathing bag contained $2000 \mathrm{cc}$. of room air at the start. The successive samples gave the results shown in the curves of figure 2 .

Two questions may be raised regarding the statement that the gases in the final gas mixture in the rebreathing bag are in equilibrium with the gases of true mixed venous blood. The first question is: do the samples withdrawn from the bag represent the gas mixture actually in contact with the blood flowing through the lungs? In other words, has there been a perfect mixture throughout the system composed of the lungs, respiratory passages, bag and the connecting tube? This question is best answered by reference to the recent work of Lundsgaard and Schierbeck (1923). They studied by an ingenious method the mixing of hydrogen and oxygen in a lung-bag system, and found that when two liters of a gas mixture were rebreathed three times following expiration to the residual air, a perfect mixture was obtained 
C. SIDNEY BURWELL AND G. CANBY ROBINSON

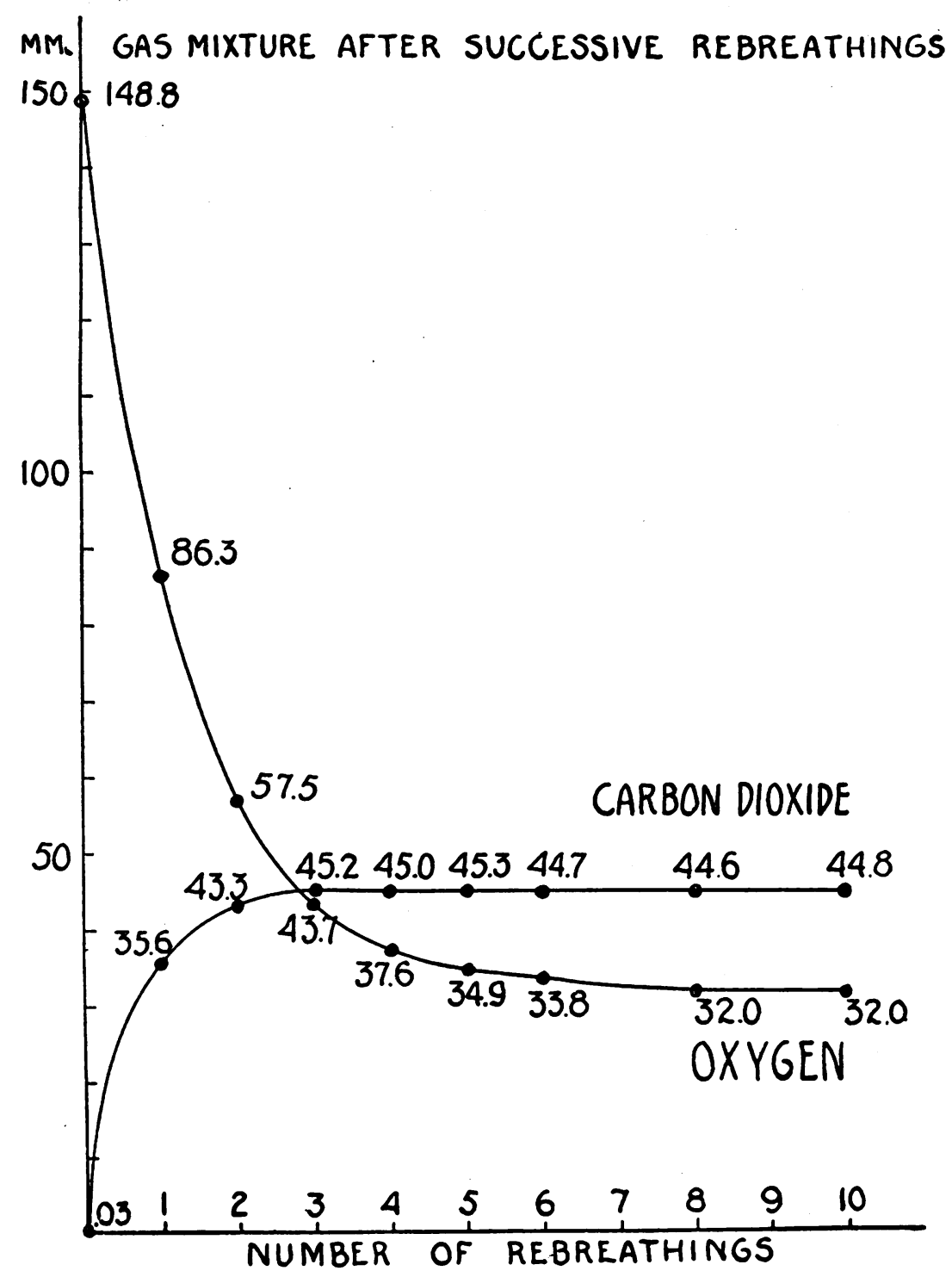

Fig. 2. Curve Constructed from the Analyses of Successive Samples $\therefore$ Withdrawn from the Rebreathing Bag After Each Rebreathing The figures give the $\mathrm{O}_{2}$ and $\mathrm{CO}_{2}$ tensions obtained by each analysis 
in both of the two normal subjects studied. Douglas and Haldane (1922) have also considered this question. Their experiments showed that by merely taking a single deep breath of a gas mixture it is impossible to produce an even mixture in the lung alveoli. When, however, there is no great relative difference between the percentage of a gas in the mixture inspired and the percentage already present in the alveolar air, this source of fallacy is of minor importance. They found that with a large difference in the percentages as in measurements of venous oxygen tension by their method at least three maximal breaths were required to obtain a perfect mixture. Our subjects rebreathed on an average 2.25 liters of air to and from the bag, the composition of which was fairly close to that contained in the lungs after two inspirations from the spirometer. We believe therefore that in the light of the constancy of our results and the experience of others that the gas samples from the bag represented exactly or very closely the mixture that had been exposed to the blood in the lungs. It is possible that in studying patients with respiratory or circulatory disorders true mixtures may not be so readily obtained.

The second question is: may the blood flowing through the lungs during the rebreathing be considered as true mixed venous blood of a resting subject? There are two factors which may so alter the blood that it is not true venous blood. One is improper aeration of the blood previous to its passage through the systemic capillaries, and the other is a change in rate of flow of blood through the systemic capillaries. In order that the first factor may not come into play, the respiratory procedure is limited in time, so that no blood that has passed through the lungs when filled with other than the normal lung contents again returns to the lungs during the procedure. Our own experiments and the experience of all other workers in this field are in agreement that for resting subjects no such error is introduced when the respiratory procedure does not exceed twenty seconds. In regard to the rate of flow through the systemic capillaries, it is known that when the blood flow is slowed, more oxygen is given off and more $\mathrm{CO}_{2}$ taken up by the blood than when the blood is flowing at its usual rate. It is probable that there is a certain amount of quickening of blood flow through the capillaries during our respiratory procedure, as during deep breathing blood is drawn more rapidly to the 
heart than during normal respiration. During the two deep inspirations from the spirometer therefore, it is probable that the blood flow is quickened, and this may result in a more rapid flow of blood through some of the systemic capillaries. It would be expected that under these circumstances a slight rise in the oxygen tension and a slight fall in the $\mathrm{CO}_{2}$ tension of the mixed venous blood would occur, as less oxygen would be given up to the tissues and less $\mathrm{CO}_{2}$ taken away when the blood flow through the capillaries was quickened. This would in turn produce an error in the final blood gas figures which would diminish the figures for oxygen utilization and for $\mathrm{CO}_{2}$ production. This possible source of error was pointed out by Barcroft, Roughton and Shoji (1921), who thought that the alteration of the rate of blood flow through the systemic capillaries produced by their respiratory method introduced a trivial error in their results. We have not been able to investigate this possible source of error directly on our own subjects, but when our figures for oxygen utilization and $\mathrm{CO}_{2}$ production are compared with those of other,s we find that there is no evidence of any diminution in the oxygen utilization or $\mathrm{CO}_{2}$ production. Our figures, as will be seen later, are usually higher than those obtained for these values by other workers in the field.

We believe therefore that all the questions regarding the proper mixing of gases and possible changes in the mixed venous blood may be answered satisfactorily, and that our respiratory method yields a gas mixture the gas tensions of which are within $1.0 \mathrm{~mm}$. Hg of the gas tensions of the blood.

The gas content of the blood. In order to determine the gas content of the mixed venous blood two $300 \mathrm{cc}$. tonometers were filled with the gas from the bag over mercury after the last rebreathing. Blood was then obtained under oil, oxalated and chilled. Approximately $6 \mathrm{cc}$. of this blood was transferred to each tonometer and they were then rotated by motor for twenty minutes in a water bath at body temperature. The excess pressure in the tonometer due to the rise in temperature was released after five minutes of rotation by opening one end of the tonometer just under the surface of the water. In most of the experiments venous blood was used for equilibration, but following a suggestion of Peters (1924), arterial blood was used also in some later ones. No difference in the gas content of the blood was observed. 
We have followed the first method described by Austin, Cullen, Hastings, McLean, Peters, and Van Slyke (1922) in equilibrating the blood. The blood was withdrawn into small sampling tubes from the tonometer while it was still immersed in the water bath, placed under oil or over mercury and kept in an ice bath until analysed. Samples of the gas mixture were taken from the tonometers after

TABLE 2

Experiment 1

May 29, 1923. Barometer 758.0. Temperature $25^{\circ} \mathrm{C}$. Subject H. Weight 66 kilos. Age 28. Average pulse rate 61 .

\begin{tabular}{|c|c|c|c|}
\hline & & Oxygen tension & $\begin{array}{l}\text { Carbon dioxide } \\
\text { tension }\end{array}$ \\
\hline & & $m m . \mathrm{Hg}$ & $m m . \mathbf{H g}$ \\
\hline \multirow{6}{*}{\multicolumn{2}{|c|}{ 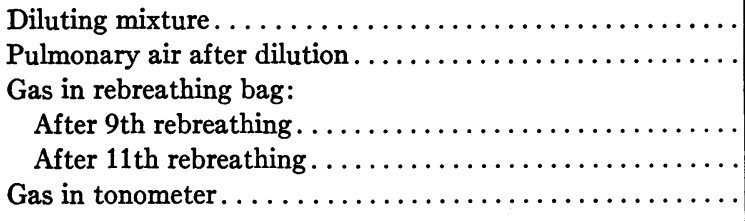 }} & 28.2 & 45.0 \\
\hline & & 38.7 & 45.4 \\
\hline & & & \\
\hline & & 36.7 & 45.7 \\
\hline & & 36.0 & 46.1 \\
\hline & & 35.8 & 45.9 \\
\hline & Oxygen content & $\begin{array}{c}\text { Carbon dioxide } \\
\text { content }\end{array}$ & $\begin{array}{l}\text { Oxygen } \\
\text { saturation }\end{array}$ \\
\hline & ool. per cent & vol. per cent & per cent \\
\hline Arterial blood . ....... & 22.46 & 43.59 & 96 \\
\hline Mixed venous blood . . . . . . . . . . & 16.41 & 48.58 & 71 \\
\hline 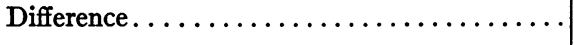 & 6.05 & 4.99 & 25 \\
\hline & $c c$. & $c c$. & \\
\hline Total gas exchange per minute............ & 231 & 182 & \\
\hline Circulatory minute volume...$\ldots \ldots \ldots$ & 3820 & 3650 & \\
\hline 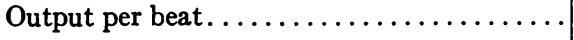 & 63 & 60 & \\
\hline Respiratory quotient, external $\ldots \ldots \ldots \ldots \ldots$ & 0.79 & & \\
\hline Respiratory quotient, internal............ & 0.83 & & \\
\hline
\end{tabular}

the blood was removed. The blood was analysed in the large model apparatus as described by Van Slyke and Stadie (1921), $1 \mathrm{cc}$. of blood being used for each analysis, and results were accepted only when the duplicate analyses checked properly. A specimen of blood was withdrawn from the brachial artery immediately after the venous blood was obtained, following the technique described by Stadie (1919), and subjected to analysis under the same conditions as the equili- 
brated blood. The subject was kept at the same state of rest while the blood samples were being withdrawn as when the respiratory procedures were being carried on.

\section{RESULTS}

Our complete experiments were carried in the following order. The subject came to the laboratory in the morning without breakfast,

\section{TABLE 3}

Experiment 2

June 5, 1923. Barometer 759.4. Temperature $28^{\circ} \mathrm{C}$. Subject H. Weight 66 kilos. Age 28. Average pulse rate 64 .

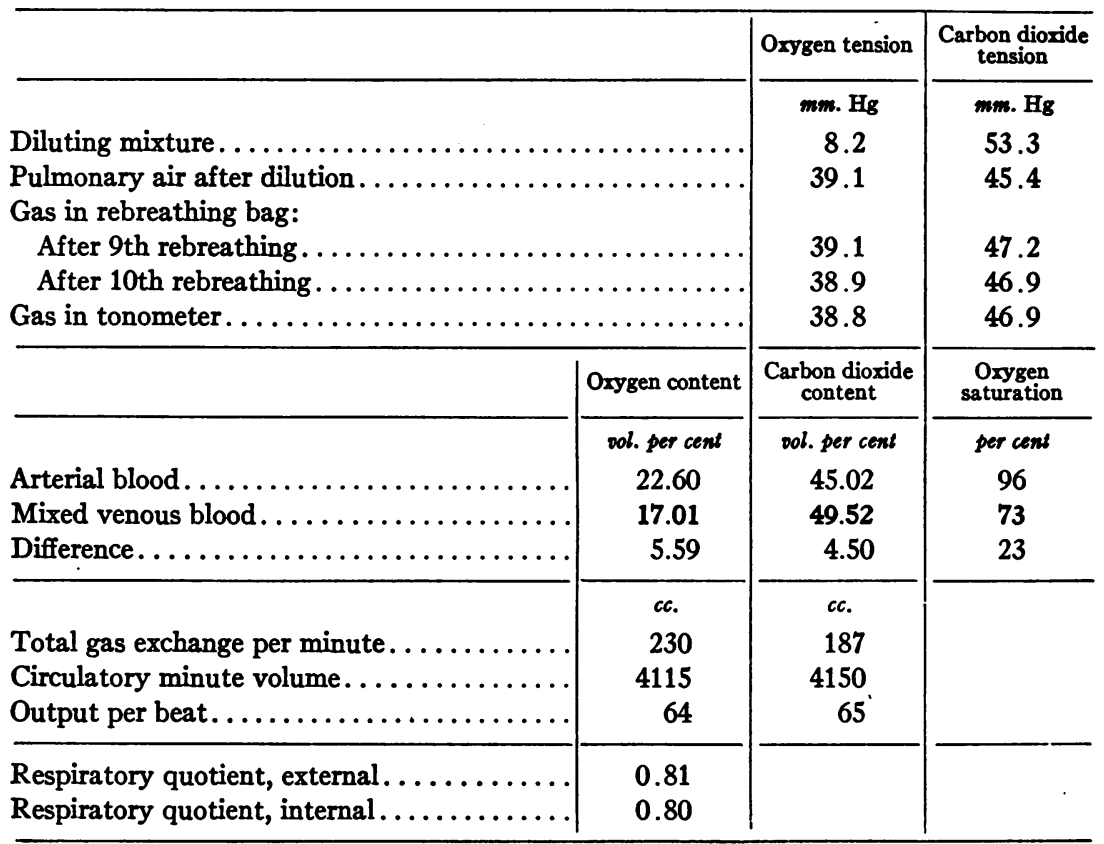

and rested in a reclining chair for half an hour, and until the pulse rate had assumed a constant low level (60 to 72 per minute). The expired air was collected during a six-minute period in a Tissot spirometer to determine the amount of oxygen absorbed and $\mathrm{CO}_{2}$ produced per minute. The respiratory procedure was then conducted as described. As soon as this was completed, venous and arterial 
blood samples were obtained, and the subject released. These procedures usually required about an hour and a half or two hours.

We wish to report as examples the results of two experiments carried out on a normal subject under similar conditions of complete rest during the post-absorptive period.

These experiments were performed on the same subject one week apart. They are in substantial agreement throughout. The last seems to be the more successful, as there is almost exact agreement of the respiratory quotients obtained from the blood gas analysis and from the gas exchange in the lungs. (Tables 2 and 3.)

It will be observed that in these experiments the circulatory minute volume calculated from the oxygen figures are in closer agreement than those calculated from the carbon dioxide figures. It may be said that in making a series of observations on the same subject the oxygen figures are much the more constant and that when great fluctuations occur they occur only in the carbon dioxide figures. This is understandable when it is considered that in determining the blood flow from the difference between the arterial and venous oxygen in normal people there is, practically speaking, only one variable since the arterial oxygen content is fixed at approximately 95 per cent of the oxygen capacity; while when the flow is derived from the carbon dioxide content of arterial and venous blood we are dealing with two variables, since the arterial $\mathrm{CO}_{2}$ content may vary with the depth of respiration.

These two experiments illustrate also the fact that the final equilibrium in the bag is independent of slight changes in the diluting mixture. Thus, in Experiment 2 a lower $\mathrm{O}_{2}$ in the diluting mixture is associated with a higher $\mathrm{O}_{2}$ in the bag than in experiment 1.

\section{COMMENTS}

We have attempted to test our method, not only by the various means already described but also by comparing our results with known physiological facts. For example, the amount of oxygen taken up by the blood in the tonometers has with the exception of one out of twelve individuals been found to fall within the limits of oxygen dissociation curves published by Barcroft (1914) and others as normal. 
The $\mathrm{pH}$ of the "mixed venous bloods," calculated from the relation of $\mathrm{CO}_{2}$ tension and $\mathrm{CO}_{2}$ content, is in agreement with the figures published by Peters, Barr and Rule for the $\mathrm{pH}$ of venous blood of normal resting subjects. We have laid particular stress upon the importance of an agreement between the relation of oxygen lost to $\mathrm{CO}_{2}$ gained by a unit of blood and the respiratory quotient determined by the Tissot method. The respiratory quotient determined by the blood gases will agree with that determined by the Tissot method only when the figures for the oxygen and $\mathrm{CO}_{2}$ contents of both arterial and venous blood are correct or else vary in the same direction and to the same extent from the correct figure. This agreement has been reasonably close in all our experiments in which some obvious error did not occur.

A consideration of our figures for the minute output of the heart is reserved for a separate paper. It may be stated here however that a comparison of blood flow figures would add very little as a check on the accuracy of any particular method, as there has been a striking lack of agreement in results obtained by different observers using different methods.

We have used standard methods of analyses and have therefore not described our analytical procedures. Our method for the most part is a combination of those that have been previously described. The technical contributions that we have made consist in the employment of alveolar air samples obtained by the Haldane-Priestly method after adjustment of the lung air, in order to determine the proper gas mixture to be used for diluting the lung air; the double rebreathing method for determining the correctness of the oxygen tension in the rebreathing bag; the method of obtaining a gas mixture in which all gases are in equilibrium with those of the venous blood; and the direct use of this gas mixture for obtaining so-called mixed venous blood by equilibration in a tonometer.

Many analyses of gas and blood are necessary to obtain all the data required for a complete experiment, but this burden falls on the workers and the procedures do not call for special training or endurance on the part of the subject. We believe therefore that our method is readily applicable to hospital patients of average intelligence who are not acutely ill. 


\section{SUMMARY}

A method for obtaining the gaseous content of the mixed venous blood of man has been developed that gives results for healthy resting subjects that fulfill practically all requirements of known physiological facts.

When the results of the method are combined with those of analysis of the arterial blood and of the determination of the gas exchange in the lungs, data is at hand for calculating the output of the heart, per minute and per beat.

The method is applicable to untrained subjects, and should be of value in the study of cardiac disease and of disturbances of the respiratory functions of the blood.

\section{BIBLIOGRAPHY}

Austin, J. H., Cullen, G. E., Hastings, A. B., McLean, F. C., Peters, J. P., and Van Slyke, D. D. Jour. Biol. Chem., 1922, liv, 121. Studies of Gas and Electrolyte Equilibria in Blood. I. Technique for Collection and Analysis of Blood, and for its Saturation with Gas Mixtures of known Composition.

Barcroft, J. The Respiratory Function of the Blood. Cambridge, 1914.

Barcroft, J., and Nagahashi, M. Jour. Physiol.; 1921, lv, 339. The Direct Measurement of the Partial Pressure of Oxygen in Human Blood.

Barcroft, J., Roughton, F. J. W., and Shoji, R. Jour. Physiol., 1921, lv, 371. The Measurement of the Oxygen Content of the Mixed Venous Blood, and of the Volume of Blood Circulating per Minute.

Christiansen, J., Douglas, C. G., and Haldane, J. S. Jour. Physiol, 1914, xlviii, 244. The Absorption and Dissociation of Carbon Dioxide by Human Blood.

Dautrebande, L., Davies, H. W., and Meakins, J. Heart, 1923, x, 133. The Influence of Circulatory Changes on the Gaseous Exchanges of the Blood. III. An Experimental Study of Circulatory Stasis.

Douglas, C. G., and Haldane, J. S. Jour. Physiol., 1922, lvi, 69. The Regulation of the General Circulation Rate in Man.

Fick, A. Sitzungsb. der phys.-med. Gesellsch. zu Würzburg, 1870, 16. Ueber die Messung des Blutquantums in den Herzventrikeln.

Fridericia, L. S. Biochem. Zeitsch., 1918, lxxxv, 307. Untersuchungen an Menschen über Sauerstoff- und Kohlensäuerespannung im Blut der Pulmonalarterie und über Messung des Minutenvolumes des Herzens.

Henderson, Y. Physiological Reviews, 1923, iii, 165. Volume Changes of the Heart.

Henderson, Y. and Prince, A. L. Jour. Biol. Chem., 1917, xxxii, 325. Applications of Gas Analysis. II. The $\mathrm{CO}_{2}$ Tension of the Venous Blood and the Circulation Rate. 
Laurens, H. Amer. Jour. Physiol., 1918, xlvi, 147. The Effect of Holding the Breath and of Rebreathing on the Rise of $\mathrm{CO}_{2}$ Tension in the Lungs, and the Determination of the $\mathrm{CO}_{2}$ Tension' of the "Venous Pulmonary Air."

Loewy, A., and von Schrötter, H. Zeitsch. f. exp. Path. u. Ther., 1905, i, 197. Untersuchungen über die Blutcirculation beim Menschen.

Lungsgaard, C., and Schierbeck, K. Amer. Jour. Physiol., 1923, lxiv, 210. Studies on the Mixture of Air in the Lungs with Various Gases. I.

Lungsgaard, C., and Schierbeck, K. Amer. Jour. Physiol., 1923, Ixiv, 231. Studies on the Mixture of Air in the Lungs with Various Gases. II. The Quantitative Influence of Certain Factors in Producing a Full Mixture of Hydrogen with Air in the Lungs.

Meakins, J., Dautrebande, L., and Fetter, W. J. Heart, 1923, x, 153. The Influence of Circulatory Disturbances on the Gaseous Exchange of the Blood. IV. The Blood Gases and Circulation Rate in Cases of Mitral stenosis.

Meakins, J., and Davies, H. W. Heart, 1922, ix, 191. The Influence of Circulatory Disturbances on the Gaseous Exchange in the Blood. II. A Method of Estimating the Circulation Rate in Man.

Peters, J. P. Jr. Personal Communication (1924).

Peters, J. P. Jr., Barr, D. P., and Rule, F. D. Jour. Biol. Chem., 1921, xlv, 489. I. The Carbon Dioxide Absorption Curve and Carbon Dioxide Tension of the Blood of Normal Resting Individuals.

Plesch, J. Zeitsch. f. exp. Path. u. Ther., 1909, vi, 380. Hämodynamische Studien.

Redfield, A. C., Bock, A. V., and Meakins, J. C. Jour. Physiol., 1922, lvii, 76. The Measurement of the Tension of Oxygen and Carbon Dioxide in the Blood of the Pulmonary Artery in Man.

Stadie, W. C. Jour. Exp. Med., 1919, xxx, 215. The Oxygen of the Arterial and Venous Blood in Pneumonia and its Relation to Cyanosis.

Stewart, H. J. Arch. Int. Med., 1923, xxxi, 871. Observations on the Blood Gases in Auricular Fibrillation and after the Restoration of the Normal Mechanism.

Uyeno, K., and Doi, Y. Jour. Physiol., 1922, lvii, 14. Studies on the Respiration and Circulation in the Cat. II. The Oxygen in the Venous Blood.

Van Slyke, D. D., and Stadie, W. C. Jour. Biol. Chem., 1921, xlix, 1. The Determination of the Gases of the Blood.

Wiggers, C. J. Modern Aspects of the Circulation in Health and Disease. 2nd edition, Philadelphia, 1923. 